\title{
Research progress on criteria for discontinuation of EGFR inhibitor therapy
}

This article was published in the following Dove Press journal:

OncoTargets and Therapy

12 October 2012

Number of times this article has been viewed

\section{Hong-qing Zhuang \\ Zhi-yong Yuan \\ Jun Wang \\ Ping Wang \\ Lu-jun Zhao \\ Bai-lin Zhang}

Department of Radiotherapy, Tianjin Medical University Cancer Institute and Hospital, Tianjin Key Laboratory of Cancer Prevention and Therapy, Tianjin Lung Cancer Center, Tianjin, People's Republic of China
Correspondence: Hong-Qing Zhuang and Bai-lin Zhang

Tianjin Medical University Cancer Institute and Hospital, Department of Radiotherapy, Tianjin, People's Republic of China Tel +86 22 2334 I405

Fax +862223341405

Email hongqingzh@163.com
Abstract: The clinical success of the epidermal growth factor receptor (EGFR) tyrosine kinase inhibitors (TKI) as therapeutic agents has prompted great interest in their further development and clinical testing for a wide variety of malignancies. However, most studies have focused on the efficacy of TKI, and few studies have been done on the criteria for their discontinuation. The current standard for drug discontinuation is "until progression", based on change in tumor size. However, tumor size is not related to the gene expression which determines the efficacy of TKI in the final analysis, and it is also difficult to make a thorough and correct prediction based on tumor size when the TKI is discontinued. Nevertheless, clinical evaluation of the criteria for TKI discontinuation is still in its early days. Some promising findings have started to emerge. With the improving knowledge of EGFR and its inhibitors, it is expected that the criteria for discontinuation of EGFR inhibitor therapy will become clearer.

Keywords: epidermal growth factor receptor, drug discontinuation, acquired drug-resistance

\section{Introduction}

As is widely known, the epidermal growth factor receptor (EGFR) is a tyrosine kinase receptor that regulates the fundamental processes of cell growth and differentiation. Overexpression of EGFR and its ligands was reported in various epithelial tumors in the $1980 \mathrm{~s},{ }^{1,2}$ and generated interest in EGFR as a potential target for cancer therapy. ${ }^{3-9}$ Intensive research efforts have been rewarded in recent years because ATP site-directed EGFR tyrosine kinase inhibitors (TKI) have been found to show antitumor activity in subsets of patients with nonsmall cell lung cancer, ${ }^{10,11}$ squamous cell carcinomas of the head and neck, ${ }^{12}$ and certain other malignancies. ${ }^{13-17}$

However, these achievements cannot solve all the problems in this field, eg, agreement on the criteria for drug discontinuation. Although these criteria are usually simplified into "until progression", it is still important to acknowledge the great complexity of this issue in the context of signal cross-talk with a large number of associated proteins. Therefore, more investigation of the criteria for discontinuation would be of great value, both in understanding how the EGFR signal pathway potentially responds and adapts when blocked by EGFR inhibitors for a long period of time at the level of basic research and in improving the effects of EGFR inhibitor therapy in clinical practice.

\section{Historical origin of current criteria}

The criteria used for discontinuation of EGFR inhibitor therapy are historical ones. On the one hand, at the early stage of development of EGFR inhibitor therapy, because 
of technical limitations at that time, a lot of fundamental knowledge and basic theoretical considerations were missing, and several factors influencing the efficacy of EGFR inhibitors could not be elucidated either. Therefore, opportunities for investigation of the criteria for drug discontinuation were limited in clinical practice, and for various reasons, it was very difficult to establish an appropriate standard for discontinuation of EGFR inhibitor therapy at that time. ${ }^{18-22}$

On the other hand, although EGFR inhibitor therapy is very different from traditional chemotherapy, the designs used for clinical chemotherapy trials in the early stage of development of EGFR inhibitors influenced the parameters and methods used in subsequent studies of gene therapy. Therefore, as with chemotherapy, change in tumor size has become the main criterion for discontinuation of treatment with EGFR inhibitors. ${ }^{23}$ However, changes in the efficacy of an EGFR inhibitor are determined by gene and biomarker characteristics rather than by Response Evaluation Criteria in Solid Tumors Group (RECIST) criteria, whereby clinical response is determined by change in tumor size. ${ }^{18}$ Progression of tumor size and progression of gene expression are by no means different forms of the same concept, and tumor size has no relationship with the efficacy of an EGFR inhibitor. Therefore, in the final analysis, the current criterion used for discontinuation of EGFR inhibitor therapy lacks a theoretical basis, and is problematic in clinical practice.

First, even though tumor size may not be increased and significant changes in EGFR-related gene expression indicate that the patient is not suitable for continuation of medication, EGFR inhibitor therapy may be continued until progression according to the current criteria. Continuation of therapy results in more drug side effects for the patient and an increasing economic burden. Second, even if there is no significant change in EGFR-related gene expression confirming that the patient is suitable for continuation of medication, an increase in tumor size will mean that the patient has to stop EGFR inhibitor therapy according to the current criteria, thereby losing the opportunity for further treatment, such that the tumor size may increase more quickly with an added suffering burden for the patient. These two scenarios indicate a clear need for further investigation of the criteria for discontinuation of EGFR inhibitor therapy.

Although the current means of assessing the efficacy of EGFR inhibitors are important for determining the usefulness of drug continuation, there is no standard for drug discontinuation at this time. Nevertheless, the standard used for TKI discontinuation is without an adequate theoretical basis, and indepth analysis of this standard has shown us that the more the experience, the less the evidence. During the early stages of clinical use of the EGFR inhibitors, the criterion of "until progression" used for drug discontinuation was reasonable to some extent because of the limitations in fundamental research and clinical experience with these agents, and has contributed to standardizing the use of this therapy. However, with the progress in fundamental research and clinical trials, this criterion has gradually fallen behind clinical practice and become an obstacle to further development of the EGFR inhibitors. In order to improve further upon the efficacy of EGFR inhibitor therapy, consideration of new criteria for drug discontinuation has become urgent in the field of cancer therapy.

\section{Discontinuation before progression versus continuation until progression}

Acquired drug-resistance determines whether or not drugs should be discontinued before progression. Cellular levels of EGFR do not always correlate with the response to a TKI, indicating acquired resistance to EGFR therapy. Morgillo and $\mathrm{Lee}^{24}$ have published a detailed review suggesting that acquired resistance can occur as a result of several different molecular mechanisms, ie, autocrine/ paracrine production of ligand, receptor mutation, constitutive activation of the downstream pathway, and activation of alternative pathways. The question of TKI discontinuation arises because of the acquired resistance problem. In the present review, we discuss four aspects of this problem, and whether long-term treatment could activate these mechanisms.

\section{Autocrine/paracrine production of ligand}

The data ${ }^{25-32}$ suggest that the presence of high levels of ligand could enhance EGFR pathways, leading to increased sensitivity to EGFR TKI, and that the presence of low levels of ligand could reduce EGFR pathways, leading to decreased sensitivity to EGFR TKI. Ferrer-Soler et $\mathrm{al}^{33}$ recently suggested that gefitinib-induced changes in endogenous levels of EGF-related ligands were correlated with the natural degree of sensitivity of cancer cells to gefitinib. While cancer cells intrinsically resistant to gefitinib markedly upregulated the expression of genes coding for HER-specific ligands, a significant downregulation of HER ligand gene transcription was found in breast cancer cells intrinsically sensitive to gefitinib. 


\section{Receptor mutations and amplification}

Receptor mutations have been shown to be important mechanisms of drug resistance for EGFR TKI. ${ }^{34}$ And lots of factors have been implicated, including EGFRvIII, ${ }^{35,36}$ exons $18-21,{ }^{37,38} \mathrm{~T} 790 \mathrm{M},{ }^{39}$ and K-ras. ${ }^{40}$ All these mutations might lead to acquired resistance to TKI. Not only receptor mutations but also receptor amplification can affect drug resistance to TKI in tumor tissue, eg, MET, a receptor tyrosine kinase for hepatocyte growth factor. Bean et $\mathrm{al}^{41}$ reported that amplification of MET in lung tumors with acquired resistance is more common than that in untreated lung tumors. Dysregulation of MET signaling has been shown to contribute to tumorigenesis in various cancers via activating mutations (eg, papillary renal cell carcinomas) $)^{42}$ or via high-level amplification (eg, gastric cancers).$^{43}$ Therefore, many mutations and amplification have a relationship with the sensitivity of TKI, and the question arises regarding whether TKI can activate these factors and influence their sensitivity to these inhibitors?

Recent studies go some way towards answering this question. Engelman et $\mathrm{al}^{44}$ isolated gefitinib-resistant clones from HCC827 lung cancer cells (EGFR exon 19 deletion and amplification) by exposing the cells to increasing concentration of gefitinib. The resistant cells, except for parental cells, harbored MET amplification, and inhibition of MET by specific TKI restored their sensitivity to gefitinib. Further, amplification of MET was found in about $20 \%$ of patients, with acquired resistance identified in only $3 \%$ of untreated patients. ${ }^{44,45}$ Interestingly, MET amplification sometimes coexisted with the T790M mutation, ${ }^{45}$ and one patient was reported to have two independent resistant tumors, one of which had the T790M mutation and the other had MET amplification. These suggest that long-term treatment with TKI might activate mutations and amplifications, and induce resistance to TKI.

\section{Constitutive activation of the downstream pathway}

The molecular mechanisms of acquired resistance can involve several processes, such as persistent activation of downstream signaling steps as well as the phosphoinositide 3-kinase (PI3K)/Akt and mitogen-activated protein kinase (MAPK) pathways. ${ }^{46-48}$ Many studies have suggested that at least one of these pathways defines a resistant phenotype unaffected by EGFR inhibitor therapy, and that p27/PTEN expression might play an important role in the outcome of treatment. ${ }^{49-53}$ These are the mechanisms of drug resistance, and also the factors that are activated when tumor cells are blocked for a long time. Further, there is some evidence that the PI3K/Akt and/or Ras/MEK/MAPK signaling pathways could be activated by TKI.

In myelogenous leukemia, ${ }^{54}$ in order to study resistance to TKI targeting FLT3, a receptor tyrosine kinase that is frequently mutated in acute myelogenous leukemia, researchers have developed resistant human cell lines by prolonged cocultivation with FLT3 TKI. The data indicate that FLT3 TKI-resistant cell lines often show continuous activation of downstream PI3K/Akt and/or Ras/MEK/MAPK signaling pathways. Mutational screening of FLT3 TKIresistant cell lines also revealed activating N-Ras mutations in two cell lines that did not exist in the parental FLT3 TKI-sensitive cell line. Considering all these observations, these data indicate that FLT3 TKI-resistant cells would can evolve into cells that are not FLT3-dependent because of activation of downstream signaling pathways that provide compensatory survival/proliferation signals when FLT3 is inhibited.

\section{Activation of alternative pathways}

Signaling through the insulin-like growth factor I receptor (IGF-IR) could represent an alternative cell survival pathway, resulting in resistance to EGFR blockade ${ }^{49,55-57}$ Two major pathways are thought to originate from IGF-IR. One is via insulin receptor substrate-1, which activates the PI3-K/Akt pathway, and the other is via Shc, which activates the Ras/Raf/ MEK/ERK pathway. It is generally accepted that activation of IGF-IR plays a key role in resistance to TKI..$^{58,59}$

In many cancer cells, acquired resistance to gefitinib has been shown to be associated with increased signaling via the IGF-IR pathway, which also plays a role in the invasive phenotype of gefitinib-resistant cells. ${ }^{60-63}$ Recently, some reports have indicated that IGF-I-induced ERK activation and crosstalk between IGF-IR and EGFR occurring via an autocrine mechanism involving matrix metalloproteasedependent release of HB-EGF accounts for most IGF-Istimulated Shc phosphorylation and activation of the ERK cascade. Similar results have been reported using mammary epithelial cells, showing that IGF-I-induced ERK activation is dependent on EGFR transactivation rather than being mediated by HB-EGF shedding. ${ }^{49,64}$ However, the real nature of this crosstalk still needs further research. Overall what we can confirm is that IGF-IR represents a cell survival pathway and IGF-1 is an important regulatory factor of TKI resistance. From a different perspective, when we block EGFR for a long 
period of time, what will happen to IGF-I, ie, when the main stream is blocked, how will the tributary change?

In summary, the autocrine/paracrine production of ligands, receptor mutation, constitutive activation of the downstream pathway, and activation of alternative pathways are all important mechanisms of acquired resistance to TKI therapy. However, the mechanisms underlying this acquired resistance are still unknown in many cases. Further clarification of the factors leading to acquired resistance is essential to maximize the efficacy of EGFR TKI therapy. Nevertheless, looking at a leopard through a bamboo tube, we can find some variation in the trend of the factors relating to drug resistance when TKI therapy is used for a long time. Further, more and more research has demonstrated that a lot of these factors may change before tumor size improves. At the same time, they are the main mechanisms of drug discontinuation before progression.

\section{Is continuation of medication necessary after progression?}

No large-scale randomized trials have been done to determine whether continuation of medication is more effective than discontinuing EGFR inhibitors after progression, and the mechanisms involved also need further research. Nevertheless, some small-scale clinical trials have provided a basis for indepth study and indicate that continuation of EGFR inhibitors might be beneficial in certain cancers.

Many patients with a gastrointestinal stromal tumor or HER2-amplified breast cancer continue to use these agents after disease progression is documented radiographically because some tumor cells still remain sensitive to imatinib or trastuzumab. Meanwhile, patients with a gastrointestinal stromal tumor and objective evidence of disease progression have been reported to suffer an acute exacerbation or appearance of symptoms after withdrawal of imatinib. Investigators have carried out positron emission tomography to show the consequences of withdrawal of imatinib in patients with gastrointestinal stromal tumors, and a "flare" in tumor metabolism has been seen to appear after stopping imatinib. Similarly, women with HER2-amplified breast cancer often continue to receive treatment with trastuzumab despite progressive disease. However, few prospective trials have been done to investigate the therapeutic role of continuing trastuzumab after development of acquired resistance, and retrospective reviews on this issue have generated conflicting results. ${ }^{65-67}$

Unlike monoclonal antibodies, TKI do not affect internalization of the receptor and is often not specific for EGFR.
In an attempt to identify any possible differences between the RGFR inhibitors available in this regard, Riely et al ${ }^{68}$ enrolled ten patients with nonsmall cell lung cancer and acquired resistance to erlotinib or gefitinib, obtained baseline tomography and 18-fluoro-2-deoxy-D-glucose (FDG) positron emission tomography scans, then restarted these patients on erlotinib or gefitinib after drug discontinuation for 3 weeks. In this study, symptoms were aggravated in patients with acquired resistance after drug discontinuation, and larger tumor sizes and increased FDG avidity in the primary tumor were seen. The symptoms resolved and FDG uptake in the primary tumor decreased after restarting erlotinib or gefitinib. This suggests that some tumor cells remained sensitive to EGFR blockade. This prospective study of ten patients who previously responded to erlotinib or gefitinib suggests continued benefit from treatment with erlotinib or gefitinib despite documented progression of disease by RECIST criteria.

There are several possible mechanisms for the observed improvements seen in the above work. Firstly, the research cited above indicates that radiographic or symptomatic exacerbation commonly occurred within 3 weeks after discontinuation of gefitinib or erlotinib, possibly because 3 weeks was long enough for clearance of the drug (more than five half-lives for gefitinib or erlotinib) and achievement of a new steady state. ${ }^{68}$ Thereafter, from the pharmacokinetic perspective, TKI might have a marked effect. Further, patients with nonsmall cell lung cancer who initially responded to erlotinib or gefitinib therapy showed progression after a median of $12-13$ months. ${ }^{69,70}$ After patients developed acquired resistance confirmed on medical imaging, continuing use of erlotinib or gefitinib would lead to a surge in the rate of EGFR T790M mutation which, in vitro, conferred resistance to treatment with erlotinib and gefitinib. However, in patients with acquired resistance, tumor cells bearing EGFR T790M represented a minority of cells, and as such, part of the tumor may remain responsive to erlotinib or gefitinib. ${ }^{71,72}$ The other signal pathway-related EGFR followed the same principles. Partially based on our anecdotal observations of more rapid progression of disease after discontinuation of EGFR inhibitors in patients who had initially responded to treatment, we hypothesize that continued treatment might be of value as well for patients with acquired resistance to EGFR inhibitors. In addition, with growing interest in intermittent tumor treatment (eg, hormonal deprivation and chemotherapy for prostate cancer), the real possibility of intermittent TKI treatment has become appealing. Intermittent tumor treatment using hormonal deprivation is generally used with treatment-free periods not 
exceeding 6 months, so drug resistance patterns in prostate cancer might be different. But in the trial, the interval time was only 3 weeks regardless of the variation tend.

\section{Outstanding questions}

Developments in basic research on the EGFR signal pathway are laying the foundations for an EGFR inhibitor discontinuation study, but further progress in fundamental research of this pathway is needed. In spite of 30 years of investigation, the EGFR and its signaling pathway are still not fully understood. Indepth and extensive research in this field is also needed to identify an intervention for overcoming resistance to EGFR inhibitors. It is not clear if there are any factors in addition to, eg, PTEN, IGFR-1, K-ras, T790M, and the exons of EGFR that participate in this process and promote drug-resistance? The more we know about the EGFR pathway, the better the chance of formulating criteria for discontinuation of TKI.

Identification of factors influencing EGFR resistance needs further research. Since there are numerous factors involved in the EGFR pathways, it will take a long time to determine whether a certain factor is correlated precisely with EGFR inhibitor resistance and influences drug discontinuation. ${ }^{73,74}$ Sometimes this may contradict the results of previous research in this field. For example, it has been reported the K-ras mutation is a predictor of resistance to $\mathrm{TKI} .{ }^{40}$ However, recent research ${ }^{75,76}$ has found that even though K-ras is mutated, the tumor cells affected are still sensitive to TKI. It is unclear which of these observations is correct, or whether there may be a difference in the effects of K-ras mutation in different tumors. Identification of factors related to drug discontinuation may also take a repeating and devious route. When identified, these factors will influence the process of establishing standard criteria for discontinuation. If an EGFR inhibitor is discontinued upon progression, what is the next therapeutic modality? In the meantime, until new criteria for progression are established at the molecular level, what treatment should we use after EGFR inhibitor withdrawal?

First, multitargeting seems to be a promising strategy. Depending on which molecular factors are activated by long-term EGFR inhibitor treatment or correlated with EGFR inhibitor resistance, we could determine appropriate alternative targeted therapy, and then block the mechanism of drug resistance, enabling tumor cells to be reinhibited. ${ }^{75,77,78}$ However, multitargeted therapy needs further research, and its potential side effects could not be ignored. In theory, the side effects of targeted therapy can be expected to be relatively few. However, with rapid development and extensive application of the EGFR inhibitors, more and more patients are being identified as being unable to tolerate the side effects of targeted therapy, even when treated for a relatively short time. When multiple targets are blocked, the added burden of more side effects would be difficult for patients to bear. At the same time, inability of patients to tolerate side effects is also a criterion for drug discontinuation, and one which is unlikely to change. ${ }^{79}$ Because of this drawback, it is inevitable that increasing numbers of patients will lose their opportunity for treatment before new "progression". On the other hand, multitargeted therapies will certainly activate more factors related to drug resistance. When more and more factors are activated, what can we do next? Moreover, when multiple targets are blocked, other factors will be activated more easily, and shorten the duration of effect of multitargeting. Should we aim at more and more targets? If so, how do we mitigate the side effects and reduce the financial burden for patients?

Second, some investigators have advocated that first-line chemotherapy might be effective in patients with resistance for EGFR inhibitors after first, second-line chemotherapy, and EGFR inhibitor therapy sequentially. The main issue here is that resistance to first-line chemotherapy might change if the chemotherapy had been used a long time earlier. However, whether resistance to first-line chemotherapy has changed needs to be explored further, and efficacy is rarely documented in the literature.

Third, more powerful EGFR inhibitors might be effective when the present EGFR inhibitors have no effect, and these also need further research and clinical investigation. ${ }^{80}$ If we continue to use EGFR inhibitors after progression, how long should they be used and how do we evaluate their benefits and side effects in patients? If we continue to use an EGFR inhibitor after progression, should treatment be continued until death or an earlier time point? Moreover, how can we weigh the suffering caused by side effects against the benefit of tumor suppression in patients on long-term treatment with these agents? Can we evaluate quality of life by the survival time? On the other hand, if we continue to use an EGFR inhibitor for a patient and the tumor is still out of control, is it appropriate to continue treatment? If necessary, how and when therapy should be added? Furthermore, how should we evaluate the efficacy of an EGFR inhibitor when it is combined with other therapeutic modalities? Clinical studies addressing these questions are rare.

It should be noted that the biological theories and hypotheses outlined here are mostly based on preclinical 
experience and have not yet been verified in clinical studies. However, there are some objective reasons for the deficiencies in the clinical trials performed to date. Firstly, in the past, TKI therapy has been used in patients who have failed chemoradiotherapy. Once patients have failed, most need to be treated with a TKI for a relatively long period and their survival time is relatively short. Therefore, although TKI treatment was used, it was difficult to observe drug resistance to TKI because of the short survival time. Secondly, EGFR signal transduction is so complex that one or two mechanisms cannot explain it clearly, which compounds further the difficulty in performing clinical trials. As a result, few people are willing to undertake research in this area. Finally, although many pharmaceutical companies will support studies on how to use a drug, not many will fund research on how to discontinue it.

\section{Conclusion}

EGFR represents a typically successful case of "gene therapy" as well as a classic case of a process where pathway research has developed into rational therapeutic strategies. However, with clinical development of the EGFR inhibitors, new challenges have continued to emerge. Reports on criteria for discontinuation of EGFR inhibitor therapy are rare at present. In our opinion, changes in delivery of EGFR inhibitor therapy should be based on changes in detection of genes and biomarkers of response for assessment of clinical benefit, rather than on changes seen on imaging. The criteria for discontinuation of EGFR inhibitor therapy will definitely need to be changed in the future. However, it is important to note that targeting EGFR is still a relatively novel approach at present, and our knowledge of how to optimize such treatment is still unclear. More fundamental research and clinical experience are needed. ${ }^{81}$

\section{Acknowledgment}

The authors are grateful to Jan Zhang for his favorable review of the research, which was supported by the Tianjin Health Bureau Science and Technology Development Fund (09KZ83).

\section{Disclosure}

The authors report no conflicts of interest in this work.

\section{References}

1. Mendelsohn J, Baselga J. Status of epidermal growth factor receptor antagonists in the biology and treatment of cancer. J Clin Oncol. 2003;21(14):2787-2799.
2. Yaish P, Gazit A, Gilon C, Levitzki A. Blocking of EGF-dependent cell proliferation by EGF receptor kinase inhibitors. Science. 1988;242(4880):933-935.

3. Gschwind A, Fischer OM, Ullrich A. The discovery of receptor tyrosine kinases: targets for cancer therapy. Nat Rev Cancer. 2004;4(5): 361-370.

4. Baselga J, Cortes J. Epidermal growth factor receptor pathway inhibitors. Cancer Chemother Biol Response Modif. 2005;22(1):205-223.

5. Leszczyniecka M, Roberts T, Dent P, Grant S, Fisher PB. Differentiation therapy of human cancer: basic science and clinical applications. Pharmacol Ther. 2001;90(2-3):105-156.

6. Zhu Z. Targeted cancer therapies based on antibodies directed against epidermal growth factor receptor: status and perspectives. Acta Pharmacol Sin. 2007;28(9):1476-1493.

7. Ciardiello F, Tortora G. A novel approach in the treatment of cancer: targeting the epidermal growth factor receptor. Clin Cancer Res. 2001; 7(10):2958-2970.

8. Harari PM. Epidermal growth factor receptor inhibition strategies in oncology. Endocr Relat Cancer. 2004;11(4):689-708.

9. Dassonville O, Bozec A, Fischel JL, Milano G. EGFR targeting therapies: monoclonal antibodies versus tyrosine kinase inhibitors. Similarities and differences. Crit Rev Oncol Hematol. 2007;62(1):53-61.

10. Kris MG, Natale RB, Herbst RS, et al. Efficacy of gefitinib, an inhibitor of the epidermal growth factor receptor tyrosine kinase, in symptomatic patients with non-small cell lung cancer: a randomized trial. JAMA. 2003;290(16):2149-2158.

11. Fukuoka M, Yano S, Giaccone G, et al. Multi-institutional randomized phase II trial of gefitinib for previously treated patients with advanced non-small-cell lung cancer (the IDEAL 1 trial) [corrected]. J Clin Oncol. 2003;21(23):2237-2246.

12. Bonner JA, Harari PM, Giralt J, et al. Radiotherapy plus cetuximab for squamous-cell carcinoma of the head and neck. N Engl J Med. 2006; 354(6):567-578.

13. Cunningham D, Humblet Y, Siena S, et al. Cetuximab monotherapy and cetuximab plus irinotecan in irinotecan-refractory metastatic colorectal cancer. $N$ Engl J Med. 2004;351(4):337-345.

14. Haas-Kogan DA, Prados MD, Tihan T, et al. Epidermal growth factor receptor, protein kinase B/Akt, and glioma response to erlotinib. J Natl Cancer Inst. 2005;97(12):880-887.

15. Mellinghoff IK, Wang MY, Vivanco I, et al. Molecular determinants of the response of glioblastomas to EGFR kinase inhibitors. $N$ Engl $J$ Med. 2005;353(19):2012-2024.

16. Barber TD, Vogelstein B, Kinzler KW, Velculescu VE. Somatic mutations of EGFR in colorectal cancers and glioblastomas. $N$ Engl $J$ Med. 2004;351(27):2883.

17. Marie Y, Carpentier AF, Omuro AM, et al. EGFR tyrosine kinase domain mutations in human gliomas. Neurology. 2005;64(8):1444-1445.

18. Montagut C, Settleman J. Targeting the RAF-MEK-ERK pathway in cancer therapy. Cancer Lett. 2009;283(2):125-134.

19. Mendelsohn J, Baselga J. Epidermal growth factor receptor targeting in cancer. Semin Oncol. 2006;33(4):369-385.

20. Pao W, Miller VA, Kris MG. "Targeting" the epidermal growth factor receptor tyrosine kinase with gefitinib (Iressa) in non-small cell lung cancer (NSCLC). Semin Cancer Biol. 2004;14(1):33-40.

21. Jimeno A, Hidalgo M. Pharmacogenomics of epidermal growth factor receptor (EGFR) tyrosine kinase inhibitors. Biochim Biophys Acta. 2006;1766(2):217-229.

22. Di Maio M, Gridelli C, Normanno N, Perrone F, Ciardiello F. Trying to compose the puzzle with all the pieces: epidermal growth factor receptor tyrosine kinase inhibitors in non-small cell lung cancer. $J$ Cell Physiol. 2005;205(3):355-363.

23. Hussain SA, Palmer DH, Spooner D, Rea DW. Molecularly targeted therapeutics for breast cancer. Biodrugs. 2007;21(4):215-224.

24. Morgillo F, Lee HY. Resistance to epidermal growth factor receptortargeted therapy. Drug Resist Updat. 2005;8(5):298-310.

25. Riese DN, Stern DF. Specificity within the EGF family/ErbB receptor family signaling network. Bioessays. 1998;20(1):41-48. 
26. Dent P, Reardon DB, Park JS, et al. Radiation-induced release of transforming growth factor alpha activates the epidermal growth factor receptor and mitogen-activated protein kinase pathway in carcinoma cells, leading to increased proliferation and protection from radiationinduced cell death. Mol Biol Cell. 1999;10(8):2493-2506.

27. Dong J, Wiley HS. Trafficking and proteolytic release of epidermal growth factor receptor ligands are modulated by their membraneanchoring domains. J Biol Chem. 2000;275(1):557-564.

28. Fan H, Derynck R. Ectodomain shedding of TGF-alpha and other transmembrane proteins is induced by receptor tyrosine kinase activation and MAP kinase signaling cascades. EMBO J. 1999;18(24):6962-6972.

29. Roudabush FL, Pierce KL, Maudsley S, Khan KD, Luttrell LM. Transactivation of the EGF receptor mediates IGF-1-stimulated Shc phosphorylation and ERK1/2 activation in COS-7 cells. J Biol Chem 2000;275(29):22583-22589.

30. Wakeling AE, Guy SP, Woodburn JR, et al. ZD1839 (Iressa): an orally active inhibitor of epidermal growth factor signaling with potential for cancer therapy. Cancer Res. 2002;62(20):5749-5754.

31. Liu B, Fang M, Lu Y, Mendelsohn J, Fan Z. Fibroblast growth factor and insulin-like growth factor differentially modulate the apoptosis and G1 arrest induced by anti-epidermal growth factor receptor monoclonal antibody. Oncogene. 2001;20(15):1913-1922.

32. Motoyama AB, Hynes NE, Lane HA. The efficacy of ErbB receptortargeted anticancer therapeutics is influenced by the availability of epidermal growth factor-related peptides. Cancer Res. 2002;62(11): 3151-3158.

33. Ferrer-Soler L, Vazquez-Martin A, Brunet J, Menendez JA, De Llorens R, Colomer R. An update of the mechanisms of resistance to EGFRtyrosine kinase inhibitors in breast cancer: gefitinib (Iressa)-induced changes in the expression and nucleo-cytoplasmic trafficking of HERligands. Int J Mol Med. 2007;20(1):3-10.

34. Wikstrand CJ, Reist CJ, Archer GE, Zalutsky MR, Bigner DD. The class III variant of the epidermal growth factor receptor (EGFRvIII): characterization and utilization as an immunotherapeutic target. J Neurovirol. 1998;4(2):148-158.

35. Learn CA, Hartzell TL, Wikstrand CJ, et al. Resistance to tyrosine kinase inhibition by mutant epidermal growth factor receptor variant III contributes to the neoplastic phenotype of glioblastoma multiforme. Clin Cancer Res. 2004;10(9):3216-3124.

36. Li B, Yuan M, Kim IA, Chang CM, Bernhard EJ, Shu HK. Mutant epidermal growth factor receptor displays increased signaling through the phosphatidylinositol-3 kinase/AKT pathway and promotes radioresistance in cells of astrocytic origin. Oncogene. 2004;23(26): 4594-4602.

37. Lynch TJ, Bell DW, Sordella R, et al. Activating mutations in the epidermal growth factor receptor underlying responsiveness of non-smallcell lung cancer to gefitinib. N Engl J Med. 2004;350(21):2129-2139.

38. Paez JG, Janne PA, Lee JC, et al. EGFR mutations in lung cancer: correlation with clinical response to gefitinib therapy. Science. 2004; 304(5676):1497-1500.

39. Yun $\mathrm{CH}$, Mengwasser KE, Toms AV, et al. The T790M mutation in EGFR kinase causes drug resistance by increasing the affinity for ATP. Proc Natl Acad Sci US A. 2008;105(6):2070-2075.

40. Pao W, Wang TY, Riely GJ, et al. KRAS mutations and primary resistance of lung adenocarcinomas to gefitinib or erlotinib. PLoS Med. 2005;2(1):e17.

41. Bean J, Brennan C, Shih JY, et al. MET amplification occurs with or without T790M mutations in EGFR mutant lung tumors with acquired resistance to gefitinib or erlotinib. Proc Natl Acad Sci U S A. 2007 104(52):20932-20937.

42. Schmidt L, Duh FM, Chen F, et al. Germline and somatic mutations in the tyrosine kinase domain of the MET proto-oncogene in papillary renal carcinomas. Nat Genet. 1997;16(1):68-73.

43. Smolen GA, Sordella R, Muir B, et al. Amplification of MET may identify a subset of cancers with extreme sensitivity to the selective tyrosine kinase inhibitor PHA-665752. Proc Natl Acad Sci USA. 2006; 103(7):2316-2321
44. Engelman JA, Zejnullahu K, Mitsudomi T, et al. MET amplification leads to gefitinib resistance in lung cancer by activating ERBB3 signaling. Science. 2007;316(5827):1039-1043.

45. Yamamoto H, Toyooka S, Mitsudomi T. Impact of EGFR mutation analysis in non-small cell lung cancer. Lung Cancer. 2009;63(3): 315-321.

46. Janmaat ML, Kruyt FA, Rodriguez JA, Giaccone G. Response to epidermal growth factor receptor inhibitors in non-small cell lung cancer cells: limited antiproliferative effects and absence of apoptosis associated with persistent activity of extracellular signal-regulated kinase or Akt kinase pathways. Clin Cancer Res. 2003;9(6):2316-2326.

47. Wymann MP, Pirola L. Structure and function of phosphoinositide 3-kinases. Biochim Biophys Acta. 1998;1436(1/2):127-150.

48. Kolch W, Calder M, Gilbert D. When kinases meet mathematics: the systems biology of MAPK signalling. FEBS Lett. 2005;579(8): 1891-1895.

49. Gilmore AP, Valentijn AJ, Wang P, et al. Activation of BAD by therapeutic inhibition of epidermal growth factor receptor and transactivation by insulin-like growth factor receptor. J Biol Chem. 2002;277(31):27643-27650.

50. Li B, Chang CM, Yuan M, McKenna WG, Shu HK. Resistance to small molecule inhibitors of epidermal growth factor receptor in malignant gliomas. Cancer Res. 2003;63(21):7443-7450.

51. Busse D, Doughty RS, Ramsey TT, et al. Reversible G(1) arrest induced by inhibition of the epidermal growth factor receptor tyrosine kinase requires up-regulation of p27(KIP1) independent of MAPK activity. J Biol Chem. 2000;275(10):6987-6995.

52. Koizumi F, Shimoyama T, Taguchi F, Saijo N, Nishio K. Establishment of a human non-small cell lung cancer cell line resistant to gefitinib. Int J Cancer. 2005;116(1):36-44.

53. Bianco R, Shin I, Ritter CA, et al. Loss of PTEN/MMAC1/TEP in EGF receptor-expressing tumor cells counteracts the antitumor action of EGFR tyrosine kinase inhibitors. Oncogene. 2003;22(18):2812-2822.

54. Piloto O, Wright M, Brown P, Kim KT, Levis M, Small D. Prolonged exposure to FLT3 inhibitors leads to resistance via activation of parallel signaling pathways. Blood. 2007;109(4):1643-1652.

55. Chakravarti A, Loeffler JS, Dyson NJ. Insulin-like growth factor receptor I mediates resistance to anti-epidermal growth factor receptor therapy in primary human glioblastoma cells through continued activation of phosphoinositide 3-kinase signaling. Cancer Res. 2002; 62(1):200-207.

56. Ullrich A, Gray A, Tam AW, et al. Insulin-like growth factor I receptor primary structure: comparison with insulin receptor suggests structural determinants that define functional specificity. EMBO J. 1986;5(10):2503-2512.

57. Sasaki T, Knyazev PG, Clout NJ, et al. Structural basis for Gas6-Axl signalling. EMBO J. 2006;25(1):80-87.

58. Jin Q, Esteva FJ. Cross-talk between the ErbB/HER family and the type I insulin-like growth factor receptor signaling pathway in breast cancer. J Mammary Gland Biol Neoplasia. 2008;13(4):485-498.

59. Hendrickson AW, Haluska P. Resistance pathways relevant to insulinlike growth factor-1 receptor-targeted therapy. Curr Opin Investig Drugs. 2009;10(10):1032-1040.

60. Jones HE, Goddard L, Gee JM, et al. Insulin-like growth factor-I receptor signalling and acquired resistance to gefitinib (ZD1839; Iressa) in human breast and prostate cancer cells. Endocr Relat Cancer. 2004; 11(4):793-814.

61. Gschwind A, Zwick E, Prenzel N, Leserer M, Ullrich A. Cell communication networks: epidermal growth factor receptor transactivation as the paradigm for interreceptor signal transmission. Oncogene. 2001;20(13):1594-1600.

62. Pierce KL, Luttrell LM, Lefkowitz RJ. New mechanisms in heptahelical receptor signaling to mitogen activated protein kinase cascades. Oncogene. 2001;20(13):1532-1539.

63. Marinissen MJ, Gutkind JS. G-protein-coupled receptors and signaling networks: emerging paradigms. Trends Pharmacol Sci. 2001;22(7) $368-376$. 
64. Ahmad T, Farnie G, Bundred NJ, Anderson NG. The mitogenic action of insulin-like growth factor I in normal human mammary epithelial cells requires the epidermal growth factor receptor tyrosine kinase. J Biol Chem. 2004;279(3):1713-1719.

65. Gelmon KA, Mackey J, Verma S, et al. Use of trastuzumab beyond disease progression: observations from a retrospective review of case histories. Clin Breast Cancer. 2004;5(1):52-58.

66. Montemurro F, Valabrega G, Aglietta M. Trastuzumab-based combination therapy for breast cancer. Expert Opin Pharmacother. 2004;5(1):81-96.

67. Tripathy D, Slamon DJ, Cobleigh M, et al. Safety of treatment of metastatic breast cancer with trastuzumab beyond disease progression. J Clin Oncol. 2004;22(6):1063-1070.

68. Riely GJ, Kris MG, Zhao B, et al. Prospective assessment of discontinuation and reinitiation of erlotinib or gefitinib in patients with acquired resistance to erlotinib or gefitinib followed by the addition of everolimus. Clin Cancer Res. 2007;13(17):5150-5155.

69. Riely GJ, Pao W, Pham D, et al. Clinical course of patients with nonsmall cell lung cancer and epidermal growth factor receptor exon 19 and exon 21 mutations treated with gefitinib or erlotinib. Clin Cancer Res. 2006;12(3 Pt 1):839-844.

70. Jackman DM, Yeap BY, Sequist LV, et al. Exon 19 deletion mutations of epidermal growth factor receptor are associated with prolonged survival in non-small cell lung cancer patients treated with gefitinib or erlotinib. Clin Cancer Res. 2006;12(13):3908-3914.

71. Kwak EL, Sordella R, Bell DW, et al. Irreversible inhibitors of the EGF receptor may circumvent acquired resistance to gefitinib. Proc Natl Acad Sci U S A. 2005;102(21):7665-7670.

72. Engelman JA, Mukohara T, Zejnullahu K, et al. Allelic dilution obscures detection of a biologically significant resistance mutation in EGFRamplified lung cancer. J Clin Invest. 2006;116(10):2695-2706.
73. Onitsuka T, Uramoto H, Nose N, et al. Acquired resistance to gefitinib: the contribution of mechanisms other than the T790M, MET, and HGF status. Lung Cancer. 2010;68(2):198-203.

74. Ciardiello F, Tortora G. EGFR antagonists in cancer treatment. $N$ Engl J Med. 2008;358(11):1160-1174.

75. Hopfner M, Huether A, Sutter AP, Baradari V, Schuppan D, Scherubl H. Blockade of IGF-1 receptor tyrosine kinase has antineoplastic effects in hepatocellular carcinoma cells. Biochem Pharmacol. 2006; 71(10):1435-1448

76. Aviel-Ronen S, Blackhall FH, Shepherd FA, Tsao MS. K-ras mutations in non-small-cell lung carcinoma: a review. Clin Lung Cancer. 2006; $8(1): 30-38$.

77. Barnes CJ, Ohshiro K, Rayala SK, El-Naggar AK, Kumar R. Insulin-like growth factor receptor as a therapeutic target in head and neck cancer. Clin Cancer Res. 2007;13(14):4291-4299.

78. Mellinghoff IK, Cloughesy TF, Mischel PS. PTEN-mediated resistance to epidermal growth factor receptor kinase inhibitors. Clin Cancer Res. 2007;13(2 Pt 1):378-381.

79. Di Mario A, Garzia M, D’Alo F, et al. Rapid leukaemic evolution in a cutaneous blastic NK-cell lymphoma initially diagnosed as pseudolymphoma. Hematology. 2007;12(2):155-157.

80. Kamath S, Buolamwini JK. Targeting EGFR and HER-2 receptor tyrosine kinases for cancer drug discovery and development. Med Res Rev. 2006;26(5):569-594.

81. Perez-Soler R. HER1/EGFR targeting: refining the strategy. Oncologist. 2004;9(1):58-67.
OncoTargets and Therapy

\section{Publish your work in this journal}

OncoTargets and Therapy is an international, peer-reviewed, open access journal focusing on the pathological basis of all cancers, potential targets for therapy and treatment protocols employed to improve the management of cancer patients. The journal also focuses on the impact of management programs and new therapeutic agents and protocols on

\section{Dovepress}

patient perspectives such as quality of life, adherence and satisfaction The manuscript management system is completely online and includes a very quick and fair peer-review system, which is all easy to use. Visit http://www.dovepress.com/testimonials.php to read real quotes from published authors. 